\title{
UTOPÍA Y DISTOPÍA EN LOS RELATOS DE VIAJES DE JAVIER REVERTE: EL CASO DE LA CANCIÓN DE MBAMA
}

\author{
Antoine Bouba Kidakou \\ Université de Maroua (Cameroun) \\ kidakou@yahoo.fr
}

RESUMEN: Considerado como el mejor escritor español de libros de viajes sobre el África negra en el siglo XX y principios del XXI, Javier Reverte ha producido numerosos relatos en los que deja sus impresiones sobre los paisajes y las culturas africanas. Sin embargo, en $L a$ Canción de Mbama, no deroga a la tradición literaria viática, consistente fundamentalmente en acercamientos utópicos o distópicos de las realidades de los espacios recorridos mediante un hábil juego con los personajes, la retórica y varios de los tópicos del género. El presente estudio pretende analizar estos elementos estructuradores de la obra, considerados como ideosemas, para descubrir los mensajes que nos comunica el relato sobre la sociedad africana.

PALABRAS CLAVE: Utopía. Distopía. Ideosema. Viaje. África.

ABSTRACT: Considered as the best Spanish writer of travel books on black Africa in the twentieth and early twenty-first centuries, Javier Reverte has produced numerous travel books in which he left his impressions on the African society. However, in La Canción de Mbama, the author does not derogate from the literary tradition of the travel books writing, consisting mainly of utopic or dystopic approaches of the visited territories through a clever use of the characters, rhetoric and some of the topics of the genre. The present study aims to analyze these structuring elements of the book, considered as ideosemas, to discover the main messages the book offers on the African society.

KEYWORDS: utopia, dystopia, ideosema, travel, Africa

\section{Introducción}

Considerado durante largo tiempo como espejo vivo y móvil de los espacios y culturas, y fuente preciosísima de informaciones indispensables tanto para contemporáneos como para la posterioridad sobre las realidades sociales referidas, el relato de viajes ha experimentado una evolución paulatina con el entrecruzamiento de las descripciones de hechos reales y ficticios, la incorporación de dimensiones metafísicas y sociopolíticas (Zygmunt, 2013; Abad, 2013). El viajero, actuando casi siempre como protagonista-narrador, pasea su espejo a lo largo de los espacios visitados, pero también casi siempre se desprenden de la orientación de ese espejo sus aspiraciones personales, o el sesgo ideológico de esa orientación. Ambas técnicas llevan finalmente a la consideración del relato como la construcción de unas realidades utópicas ${ }^{1}$ basada en lo distópico entendido como la descripción de lo feo y lo indeseable. ${ }^{2}$

La Canción de Mbama es una historia de humanitarismo occidental hacia los pueblos primitivos de África (Guinea Ecuatorial): Luis Urzaiz, un joven médico español lleno de

\footnotetext{
${ }^{1}$ Nos referimos a la utopía en el sentido que le dio el inglés Tomás Moro, es decir para designar un orden social perfecto pero inalcanzable, un paraíso intangible y contrapuesto al mundo existente, un mundo o unas realidades ideales.

${ }^{2}$ El término distopía, de origen anglosajón, fue empleado por primera vez en 1868 por el inglés John Stuart Mill para referirse a una utopía negativa: la que describe un mundo imaginario claramente indeseable, en el que suele sacrificarse la libertad de sus ciudadanos en beneficio de otros fines, por lo general poco altruistas
} 
ilusiones, viaja a Guinea Ecuatorial apenas terminada su formación como médico, con el propósito de ofrecer sus servicios a los más necesitados (la población indígena). El contacto con las realidades de África y más precisamente, los paisajes agresivos y la violencia característica de sus nuevos dirigentes en los primeros años de independencia, las enfermedades tropicales, la presencia masiva de las serpientes y cocodrilos que comparten espacios con los hombres acaban transformando radicalmente al médico a lo largo de los años que lleva viviendo en esas tierras. La selección de esas realidades descritas por el autor, y sobre todo las consecuencias de la obstinación del médico a seguir en las tierras africanas a pesar de todas esas adversidades (ruptura de su matrimonio, separación con sus hijos, frecuentes achaques y riesgos permanentes) nos llevan a interesarnos a los aspectos semánticos pertinentes de la obra y a formular las siguientes hipótesis:

-la elección de los protagonistas de la obra y la descripción de sus acciones constituyen una técnica para la construcción de una utopía de Occidente basada en el bienestar y el altruismo; -la descripción de las realidades africanas con propensión a una focalización sobre los aspectos repugnantes y feos es una técnica para la creación de una distopía de la sociedad negra en contraposición a la utopía occidental;

-tanto la utopía occidental como la distopía social negra son herramientas que maneja el narrador para colmar en el relato los retazos de una ideología basada en estereotipos;

-finalmente, el viaje al espacio negro es una excursión en un mundo maravilloso y fantástico en un trasfondo de discurso hecho de tipología analógica y antitética.

Para analizar estos fenómenos de utopía y distopía considerados como técnicas de representaciones utilizadas en el relato a modo de hilo estructurador del discurso, convocamos la sociocrítica crosiana en sus aspectos ideosémicos ${ }^{3}$. Dicho lo cual, es preciso examinar cómo se construyen en La Canción de Mbama la utopía y la distopía.

\section{La distopía de la sociedad africana}

La historia del relato se construye, como queda dicho, entorno al viaje y a la estancia de un joven médico español, Luis Urzaiz, en una Guinea Ecuatorial que apenas sale de colonización. El joven médico pretende establecerse en este país africano para ofrecer sus servicios a los más necesitados (los Negros). El sol, los paisajes inhóspitos, la violencia y la barbarie de los lugareños acaban transformando profundamente al protagonista en su manera de ver la vida, hasta tal punto que considera su trabajo y su presencia en ese espacio como obra digna de merecer un premio Nobel. Después de la independencia las realidades se ajustan al nuevo orden sociopolítico, dando lugar a unas apreciaciones plasmadas en el relato, entre decepciones, fatalidad y afropesimismo. Años después de su llegada, convertido ya en un hombre maduro que ha visto vencidas la mayoría de sus ilusiones, se aferra a la esperanza de que en la gélida ciudad de Estocolmo premien los esfuerzos y las penurias que ha sufrido durante estas décadas concediéndole el Premio Nobel de la Paz.

La distopía (utopía negativa), se manifiesta en La Canción de Mbama ya a partir de la consideración de este espacio como una tierra donde se juega la vida. Llevar varios años viviendo en este país convierte al acto en un hecho heroico digno de recompensarse. La descripción del espacio africano con una tendencia pesimista, escéptica y una propensión a la presentación de las realidades socioculturales, históricas o económicas desde una perspectiva

\footnotetext{
${ }^{3}$ Recordemos que Cros concibe el ideosema como un articulador semiótico y discursivo a un tiempo; un concepto que designa simultáneamente el punto de origen de la estructuración y cada uno de los elementos que reproducen este origen en el texto.
} 
espeluznante y fea se convierte en estilo predilecto. Desde el principio de la obra se presenta el espacio africano por metonimia (Cogo) como un lugar de "viviendas miserables" (p. 14), “...un territorio azotado por las enfermedades, la desidia, el robo, la corrupción, la incultura y, en ocasiones, el crimen" (p.21). En la construcción de esa distopía el autor utiliza también otras modalidades que se desglosan en las líneas que siguen.

\section{I.1. Los estereotipos y los prejuicios}

Los estereotipos y los prejuicios se ofrecen como los tópicos a los cuales el narrador recurre para referirse a las realidades socioculturales africanas (guineanas). Tanto en la caracterización de los personajes negros como en los aspectos temáticos abordados, trasparece una analogía entre realidades negroafricanas y un universo oscuro, misterioso y $\sin$ expectativas.

\section{I.1.1.La descripción esperpéntica de los personajes negros}

La descripción que se hace de los personajes en el relato desvela el valor funcional que tienen en la trama de las relaciones contextuales y llevan esos personajes una carga semántica. Desde esta perspectiva, las técnicas de caracterización utilizadas pueden considerarse como las mejores claves para comprender el o los diferentes mensajes del relato.

Una primera clave de lectura e interpretación viene de la elección de los tipos y del número de personajes negros descritos. El número de personajes negros citados nominalmente que desfilan en La Canción de Mbama no es muy elevado: son principalmente Mbama, Macías Nguema, Obiang Nguema. A la limitación de este número se añade otro criterio: su función simbólica (son todos miembros de la nueva administración guineoecuatoriana). Otro aspecto digno de señalarse es el papel asignado al personaje colectivo: la población guineana. Este personaje se refiere al conjunto de los habitantes de Guinea que no sean miembros de la administración. Al señalar los aspectos específicos del retrato de los personajes mencionados se podrían percibir los mensajes que subyacen a esos retratos.

\section{Mbama}

Se presenta en el relato como un jefe guerrero en la época de Macías Nguema. Lo esencial sobre su personalidad viene señalado en el fragmento que sigue:

Era un hombre alto, fornido, de piel muy oscura, ancha nariz, frente estrecha en la que brillaban pequeñas gotas de sudor, entrecejo cerrado y mejillas surcadas por las cicatrices de una antigua viruela. Vestía un pantalón corto de color beige, una camisa del mismo tono, cruzada por un correaje bajo las rodillas y unas pequeñas botas, que llegaban algo más arriba de los tobillos. Portaba una pistola en el cinto y una fusta en la mano. Se cubría con un salacot blanco (p. 92). ${ }^{4}$

De este retrato sobresalen unos cuantos elementos simbólicos: se describe a Mbama con un halo de negritud. Según nos da a conocer el narrador en este fragmento, como es el caso en otras páginas del relato, Mbama es el un prototipo del africano embrutecido. Temido por todo el pueblo, todos piensan que su alma es la de un diablo. Viola a las mujeres y asesina placenteramente a la gente, como afirma Pilar, una profesora española que vive en Guinea: "Mbama me ha tenido secuestrada aquí todos estos años...Y me violaba cada vez que

\footnotetext{
${ }^{4}$ La edición de La Canción de Mbama manejada en este trabajo es la primera, de 1991.
} 
venía al pueblo" (p. 160). La evocación del nombre de Mbama provoca un pánico, hasta tal punto que una canción fue inventada para advertir de su misteriosa, amenazadora y peligrosa presencia:

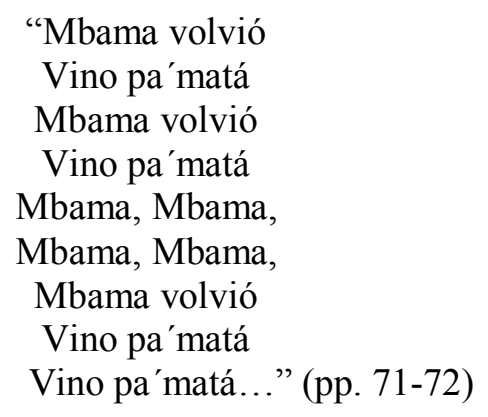

Esta canción se repite en la página177, es decir casi al final de la obra: un peligro permanente de muerte acecha a toda la población por la presencia de Mbama.

En otro fragmento, se señala que en marzo de 1969, cuando fracasó el golpe de Estado en Guinea Ecuatorial, el teniente Teodosio Mbama entró en la ciudad de Cogo al mando de una veintena de policías y se instaló en la antigua residencia de oficiales españoles previamente expulsados con extrema brutalidad. Decenas de personas fueron fusiladas en los suburbios de la ciudad y esos asesinatos se achacan al teniente Mbama. La crueldad del personaje llevó a pensar que Mbama era un personaje con doble faceta: era una confluencia de la esencia y del espíritu diabólico. Por toda la ciudad comenzó a correr un rumor: el Evú del cocodrilo se había reencarnado en el alma de Mbama.

La técnica consistente en la presentación de Mbama, un alto cargo en las fuerzas de seguridad, podría interpretarse en otro nivel: a partir del comportamiento de Mbama, de sus relaciones con los demás personajes, la posible conclusión a la que nos quiera llevar el narrador es que los dirigentes guineanos poscoloniales no estaban preparados para conducir una administración organizada, ni menos dirigir el país a partir de unas normas reguladoras pertinentemente implementadas. De ahí la sustitución de la fuerza de la ley por la ley de la fuerza en el ejercicio de la cual se ilustra Mbama.

\section{Macías Nguema}

Se identifica en el relato como el primer presidente que tuvo Guinea Ecuatorial después de su accesión a la independencia ${ }^{5}$. El narrador lo presenta como una persona adicta a las prácticas de la magia negra y la brujería. Para ilustrar esta afirmación, se describe cómo, después del golpe de Estado fallido en 1969, Macías Nguema se dedicó de manera profusa a ceremonias de buyi para conjurar toda actuación contra su poder. La peculiar asociación del poder político-administrativo con la hechicería o la brujería es el exponente de una propensión a la experpentización de los emblemas de la administración poscolonial. presidente:

Además de la brujería, la crueldad y la barbarie son otros rasgos que caracterizan al

En noviembre, cuatro años después de que se iniciase el proceso de autonomía de Guinea y siete meses desde que Luis llegara a Cogo, Francisco Macías fue proclamado presidente de la

\footnotetext{
${ }^{5}$ En la historia real de Guinea Ecuatorial este personaje ha existido como primer presidente después de la independencia. El relato cobra, con estos aspectos y otras numerosas referencias a eventos y personajes históricos, un carácter documental característico de los relatos de viajes.
} 
República. Hubo algunos festejos en la pequeña ciudad, más artificiales que sentidos por la gente. En diciembre, algunos cadáveres comenzaron a descender de los ríos al estuario. La mayoría bajaban descompuestos, sin ropas, muchos de ellos devorados en parte por los cocodrilos. Y dejaban un olor nauseabundo a su paso.

A Cogo llegaban rumores sobre las matanzas cometidas por los hombres de Macías en todo el país. (pp. 88- 89)

Para añadir otro rasgo repugnante de su personalidad: el canibalismo, se puede leer este otro fragmento:

Según contaban, Macías estaba en manos de los brujos, asistía a diario a ceremonias de buji, tomaba iboga de forma constante y había comenzado a comer carne humana. (p. 151)

Según Krummrich (2012: 3) "A lo largo de la historia de los relatos de viaje, empezando con la Odisea, si no antes, ha sido casi automático atribuir la antropofagia a los habitantes de las partes remotas del mundo, y en especial a los de las selvas". Como posible explicación o motivación del uso de esta modalidad por los escritores viajeros, el crítico baraja unas pistas políticas y literarias:

Con propósitos políticos o literarios, puede ser muy útil atribuir esta costumbre tabú a ciertos grupos. Así se han justificado los ataques contra las tribus indígenas del Caribe y de la costa de Brasil. Así los autores de libros sobre aventuras en el Congo y la región amazónica han añadido una atracción mórbida a sus narrativas (Krummrich, 2012: 3).

Al poner juntos todos estos aspectos del carácter del presidente, se podría llegar a barajar como clave de interpretación que, el autor, mediante la exageración de los rasgos característicos de este personaje, satiriza elegantemente los estereotipos y las ideas que los europeos suelen tener de los diferentes estamentos sociales negroafricanos: en vez de proclamar directamente su indignación por las prácticas denunciadas, el narrador se limita a describirlas suscitando así una indignación paralela y equivalente en los lectores. En este aspecto, cabe señalar que el autor demuestra un buen manejo de las convenciones de las narrativas de viajes que, en general, adoptan un estilo basado en un juego hábil de las combinaciones de la descripción y de la narración cuando se refieren a las Mirabilia.

\section{Obiang Nguema}

Las primeras informaciones sobre Obiang Nguema en la obra vienen insinuadas en un fragmento que alude al clima sociopolítico que coincide con su toma del poder:

Los primeros síntomas de que algo grave había sucedido en el país llegaron a Cogo en la acostumbrada forma macabra a principios de agosto de 1979: decenas de cadáveres descendieron de los ríos, como si hubiera un acuerdo milenario entre la historia y el estuario del Muni para marcar las fechas señaladas con cuerpos que se pudrían, hinchados y flotando rumbo al mar. Esta vez, muchos bajaban vestidos de uniformes de soldados. (pp. 166-167).

La información que se ofrece en este fragmento remite a la matanza que sucedió a los acontecimientos del 3 de agosto de 1979 y días siguientes, cuando se produjo el derrocamiento del presidente Macías Nguema por su sobrino Teodoro Obiang Nguema. Las precisiones sobre este personaje se dan líneas más adelante, al describir las circunstancias de su accesión al poder: 
Un « taxi-país» llegado de Bata unos días después trajo la noticia: Teodoro Obiang, sobrino del dictador Macías y coronel del ejército, educado en España, había apeado a éste del poder por medio de un inesperado súbito golpe de Estado. Apenas se habían producido algunos combates en Malabo y en Bata. En el resto de Guinea Ecuatorial, las tropas de Macías habían entregado sus armas sin resistencia. Pero los militares alzados habían fusilado a numerosos soldados leales. (p. 167)

Obiang Nguema inicia su reino con una serie de matanzas, con la violencia y la represión. Además de la caracterización de Obiang como dirigente sanguinario, la evocación de las matanzas y otros crímenes atribuidos a su régimen establece un paralelismo entre el anterior régimen (el de Macías Nguema) y éste; de modo que el mensaje fundamental a retener es la esencia bárbara y cruel de los gobiernos postcoloniales en esta parte del continente africano.

\section{I.1.2. La distopía del personaje colectivo}

La población guineana, en varios fragmentos del relato, se presenta y actúa como un personaje. Este personaje colectivo se caracteriza principalmente en el relato por su pobreza visceral, una vulnerabilidad ante todas las enfermedades, su salvajismo, su propensión a la violencia y al fetichismo; todo ello en un trasfondo de inconsciencia. Se ve, a través del tratamiento de este personaje, una intención consciente y voluntaria del narrador en el desplazamiento de lo individual hacia lo colectivo, y más precisamente un desplazamiento de lo individual-temporal hacia lo colectivo-espacial con el designio de asociar la colectividad referida al espacio referencial. En esta asociación se anula el tiempo, implicando así un aspecto sociológico de las realidades descritas: los aspectos característicos de la población guineana descritos adquieren el estatuto de rasgos definitorios de la personalidad de este pueblo. Desde esta perspectiva analítica, la presentación de la población guineana es una transposición de de los topos y topoï sobre África y los africanos, presentes en varios relatos de viajes anteriores (León el Africano, 1550; Mármol Carvajal, 1573; Barros, 1622, Pellicer de Ossau Salas y Tovar, 1649; Fernández de Navarrete, 1837, Barley, 1979). En el imaginario colectivo occidental el continente es habitado por una población monstruosa, tanto por la bestialidad de sus hombres como por su extraño modo de vida. Ilustran perfectamente esta reflexión las alusiones increíbles que hicieron muchos viajeros europeos sobre los pueblos descubiertos a lo largo de sus recorridos.

Resumiendo la imagen de África que se tenía en Occidente en aquellos siglos, y que luego se reproducen en los siglos posteriores, decía Serafín Fanjul (1995: 15):

...Los europeos aplican un reduccionismo indefendible al hablar de África: tierra cerrada (por la naturaleza, el calor, el sol, los animales salvajes); tierra de humanos incompletos ( $\sin$ nombre, como los atlantes; con lenguajes de aullidos, como fieras ), a medio camino entre el hombre pleno y la bestia, monstruosos con frecuencia y localizados, también en muchos casos en Etiopía, tierra en que las licencias sexuales acaparan la atención de los escritores (ofrecimiento de la novia a los invitados, posesión de hijos en común, etc..) y subraya la proximidad al mundo animal de los habitantes.

Estos tópicos o estereotipos que se pueden considerar como plasmación de una transtextualidad en los libros de viajes no son una innovación: constituyen uno de los 
constantes en los libros de viajes desde la Edad Media y se manifiestan en forma de evocación de espacios extraños y de lo maravilloso en sus diferentes facetas: lo maravilloso en el sentido positivo (riquezas fabulosas en oro, pedrerías preciosas y especias de todo tipo, razas humanas que gozan de una longevidad increíble o que llevan una vida purísima y que se gobiernan por leyes irreprochables, o que tienen una religión única como en el caso del imperio del Preste Juan en varios relatos) y en el sentido negativo (abundancia vegetal lujuriante y fauna de gran tamaño, licencias sexuales extravagantes y fuera del común, desnudez corporal con descubrimiento de formas físicas y hábitos alimenticios extraños por lo repelente, monstruos humanos y animales y espacios estructurados como paradigmas infernales...) Esta segunda modalidad, la distópica, es la que elige el autor de La Canción de Mbama".

\section{I.2. Temática}

La temática de más relevancia en la obra se relaciona estrechamente con la caracterización de los ecuatoguineanos en particular y de los africanos en general. Se articulan entorno a unas realidades que pertenecen al mismo registro semántico: lo feo, lo repugnante, lo peligroso, lo grosero.

\section{I.2.1. La barbarie}

Es interesante apuntar que los elementos que remiten a la barbarie característica del pueblo guineano son tan recurrentes que salpican todo el relato. Uno de los fragmentos en los que se describen los comportamientos bárbaros de los guineanos, y sobre todo de sus dirigentes, reza como sigue a continuación: “...decenas de cadáveres descendieron de los ríos, como si hubiera un acuerdo milenario entre la historia y el estuario del Muni para marcar las fechas señaladas con cuerpos que se pudrían, hinchando y flotando rumbo al mar" (p.166).

La matanza se considera aquí como uno de los mayores exponentes de la barbarie que el narrador utiliza para establecer la diferencia entre los africanos y los occidentales.

Otro tipo de barbarie en el que se insiste en La Canción de Mbama es la agresividad. Unos personajes son presentados como seres agresivos, situándose sus comportamientos entre salvajes y humanos. Mbama es la encarnación de este tipo de personajes, tal como afirma uno de los personajes femeninos de la obra, Pilar: “(...) me violaba cada vez que venía al pueblo" (p.160). Pero también los soldados en general son descritos como unos bárbaros, agresivos y crueles:

De pronto, el soldado que se sentaba a su lado [de Luis] gritó alborozado algo en fang, mientras señalaba más allá de la proa. Luis pudo distinguir que algo flotaba en el agua. Era un cadáver. Los tres policías comenzaron a dispararle con sus carabinas. Se reían cuando un proyectil se incrustaba en el cuerpo del muerto... Estaba de espaldas, desnudo, y varios agujeros de bala atravesaban sus nalgas, sin que se apreciara la presencia de sangre (pp. 155156).

\section{I.2.2. La brujería}

La brujería es una práctica corriente y generalizada, varias veces señalada en el espacio descrito, por la natural consideración de esas prácticas como parte integrante de la tradición. Pero la peculiar descripción que hace el autor de esas prácticas apunta la extraña irracionalidad que constituye la base de esta cultura. Esta postura ante lo extraño lleva al narrador a detenerse en ciertos elementos relativos a la brujería que dan lugar a extensas 
descripciones. Uno de los fragmentos que se dedican a estas realidades es el que cuenta la historia del gran reptil que buscaba un cuerpo en el que reencarnarse:

Una mañana, por esas mismas fechas, un grupo de hombres asustados subió corriendo hasta el hospital en busca de Luis, para informarle de que un gran cocodrilo, el mayor nunca visto en Cogo, había salido del estuario en el barrio de Cogo chico, al norte de la ciudad, junto al viejo aserradero vasco, y había matado y devorado a dos cabras. (...). Durante los días siguientes, al doctor, le llegaron las extrañas noticias: los brujos afirmaban que el gran reptil era una encarnación del demonio evu, una deidad maléfica, y que, al asesinarle, su alma transmigraría hacia el cuerpo de un hombre maligno. Los hechiceros realizaron varias ceremonias de buji, magia negra destinada a quebrar el maleficio, pero no habían logrado romperlo y el terrible cocodrilo buscaba en Cogo un cuerpo en el que reencarnarse para ejercer su venganza sobre sus asesinos (pp. 89-90).

La actitud de los habitantes de Cogo ante la realidad descrita, más allá del carácter supersticioso de los africanos, apunta la irracionalidad de su cultura que ignora la experiencia científica como medio de conocimiento e interpretación de los fenómenos naturales. La generalización de esta irracionalidad a todas las clases y a todos los estamentos sociales viene confirmada por la evocación de las actuaciones del presidente Macías Nguema que, durante las ceremonias de buji, utiliza a los brujos para comer la carne humana con el fin de blindarse contra la encarnación del evu del cocodrilo.

\section{I.2.3. La pobreza}

Las referencias a las condiciones de vida de los guineanos dejan percibir una generalización del déficit de capacidades básicas: una pobreza endémica.

La pobreza se presenta en el relato como una realidad permanente y generalizada entre los Negros: "Cogo no cuenta con agua corriente ni con alcantarillado. La comida escasea en la ciudad (...)" (p. 17).

Pero lo que llama más la atención es la evocación antitética de la situación de los Blancos que, en este océano de miseria, ostentan una opulencia. Estas palabras de Mbama ilustran la "superioridad" de los Blancos: "cuando era un niño, yo buscaba comida en los cubos de basura de los blancos" (p. 96-97).

\section{I.2.4. La perversión}

La perversión es otro rasgo apuntado en el relato como vicio de los africanos. Entendida como anomalía del comportamiento humano cuyo máximo exponente es la desviación de la moral y de la ética.

Una de las realidades que describe el narrador como muestra de la perversión de los africanos es la pedofilia. En África la corta edad de una chica no es un obstáculo para un varón en las relaciones sexuales. La pedofilia es, entonces, un hecho corriente y banal, practicada por los africanos y sus anfitriones. La relación entre Luis y Ceferina, casi impuesta por Mbama, es un ejemplo elocuente de esta realidad:

Al término de las danzas, Mbama señaló hacia las mujeres -Elige a una, la que más te guste. Luis dudó. ¿Yo...? Mbama dejó escapar una bronca carcajada. Claro, tú! ¿No necesitas una mujer? Todos las necesitamos. Escoge la que quieras, doctor, y llévatela arriba. En el dormitorio, antes de quitarse la falda de escobilla y unas pequeñas bragas, Ceferina, la chica 
elegida le dijo que tenía trece años. La cabeza de Luis zumbaba y sus miembros ardían de deseo. Era consciente de lo que estaba haciendo, pero la vehemencia de sus sentidos vencía con facilidad a sus convicciones y a su fe. Sabía que pecaba contra todo mientras gemía de placer al moverse sobre el cuerpo desnudo de la niña (pp. 102-103).

La depredación sexual a la que se entrega Mbama y a la que invita a Luis, como se puede notar en este fragmento, se ofrece como un aspecto denotativo de la perversión, con una implicación connotativa de la barbarie característica de la sociedad negroafricana.

\section{La utopía occidental}

Al lado del discurso despreciativo sobre las realidades africanas y de la descripción esperpéntica de su población, encontramos en el relato otro tipo de discurso, con otro tipo de argumentación que consiste principalmente en ensalzar la cultura occidental, presentada sigilosamente en la obra como modelo de referencia. La consideración de lo occidental como ideal se convierte entonces en una proyección del mundo africano, en la que se desea la construcción de unas realidades socioculturales ideales que sustituyan las vigentes. El narrador utiliza varias técnicas para invitar a esa proyección.

\section{II.1. La apología de la cultura occidental}

La idea de la cultura occidental como modelo deseado para los africanos viene insinuada en la caracterización de los personajes blancos del relato como modelos y unos discursos que presentan la sociedad española como ideal.

\section{II.1.1. Caracterización de los personajes blancos.}

\section{Luis Urzaiz}

Luis es el hijo único crecido en el seno de una familia adinerada de ascendencia liberal. Después de sus estudios, este joven médico decide viajar e instalarse en África (Guinea Ecuatorial). El objetivo es ayudar a la población guineana a luchar contra las enfermedades que la aquejaban y mejorar las condiciones de salud de los africanos. El compromiso de Luis Urzaiz en esa empresa "salvadora" es tan profundo que acepta separarse de su familia:

Luis vivía solo en Guinea desde que, en 1969, su mujer y su hijo José María, nacido en Cogo en 1968, abandonaron al país. Había llegado con ella dos años antes, pero Mari Ángeles y el niño debieron de huir durante los disturbios de marzo de ese año, cuando el presidente Macías, unos meses después de declarase la independencia desató una violenta campaña contra los residentes españoles, lo que obligó al ejército español a organizar una repatriación de urgencia en la que siete mil personas abandonaron Guinea en cuestión de unos días (p. 25).

Cuarenta años después del inicio de esa aventura caritativa en la que invirtió toda su vida, Luis se encuentra transformado, enajenado y deformado por África:

Sus hijos le resultaban extraños. Habían asumido los valores de su familia materna. Eran buenos estudiantes, desde luego; comedidos y educados, se sentían orgullosos de ser pamplonicas, una expresión que a Luis se le hacía un poco detestable, como si significara en cierta medida el orgullo de dar la espalda al mundo. Nadie le preguntaba nunca por Guinea, ni 
siquiera sus hijos. Y eso le parecía raro. ¿Por qué un niño no siente curiosidad hacia un país lejano? No podía entender la frialdad de aquellos dos críos nacidos de su sangre. Daba la impresión de que Guinea en su familia, era una palabra maldita (p. 129).

Más allá de la descripción del humanismo que anima a Luis en su proyecto para los guineanos y de su desilusión final, estos fragmentos refuerzan la distopía de la sociedad africana, en cuanto que corroboran las ideas preconcebidas sobre la incapacidad de los Negros a idear e implementar unos valores sociales compatibles con el bienestar individual y colectivo y el progreso social. El caso de la obstinación de Luis Urzaiz a ayudar a estos pueblos se ofrece entonces como auténtico desperdicio de energías y de conocimientos:

Ella tenía razón: las amaba a los dos, a Melita y a Guinea, el país al que había consagrado todas sus energías, el lugar del mundo en el que había volcado el caudal de sus esfuerzos y sus sentidos, la tierra por la que había sacrificado su vida entera. Y también el país que, en cierto modo le había convertido en un prisionero durante años. Pensó ahora, de pronto, que su estancia de muchos años en África y su biografía no se reducían a las de un médico como cualquier otro afincado en una región insalubre. El había hecho mucho más, había ayudado a levantar un hospital, había salvado decenas o quién sabe si centenares de vidas, había logrado establecer un pequeño rincón de esperanza en un territorio azotado por las enfermedades, la desidia, el robo, la corrupción, la incultura y, en ocasiones, el crimen. Su tarea no había sido humana, sino en cierto sentido casi la de un titán. De alguna manera pensaba que la suya era la biografía de un mártir (pp. 21-22).

En contraposición de la sociedad africana que ha destrozado la vida de Luis, el autor presenta lo que hubiera sido la vida de este joven médico en Occidente:

Cualquier señora de los clanes de alcurnia de la umbría ciudad lo hubiera elegido como marido ideal para sus hijas, no solo por su fortuna, sino por el prestigio de su apellido...Y de pronto, para ese joven de veintiséis años que había imaginado una vida sin sobresaltos, entregado al prójimo a través de su profesión de médico y creando una familia en la tradición legada por las generaciones que le precedieron, África surgió en el horizonte como una sombra extraña. (pp. 83-84)

\section{Pilar}

Pilar es presentada en el relato como una profesora que impartía clases en el colegio de las monjas. Es una chica que no había cumplido aún los veinticinco años. Por su oficio, similar al de Luis Urzaiz y del padre Diego por su impacto sociocultural, Pilar es otro símbolo de la empresa salvadora de Occidente en la tierra de los Negros (Guinea). Su papel: combatir la ignorancia, inculcar valores y una civilización a los guineanos a través de la educación. Como Luis, se presentará como víctima de este espacio inhóspito y de esta población salvaje. Tres semanas después de la llegada de Mbama, desapareció y nadie supo decir adonde había ido: "Pilar habló con voz muy baja, entre sollozos- ese hombre (...) Mbama, me ha tenido secuestrada aquí todos estos años... Y me violaba cada vez que venía al pueblo. No quiero tener ese hijo doctor Luis" (p. 160).

Ese secuestro transformará precisamente la estancia de Pilar en Guinea en un verdadero infierno que le causará un trauma y la muerte al final. Después de su secuestro, Mbama la lleva a un pueblecito en el bosque, a cuatro horas de Cogo remando en cayuco. La casa donde tiene secuestrada a Pilar corresponde a un viejo caserón cerca de aserradero que recuerda el tempo de la colonización española. 
Encima del río se alzaba un caserón de madera y, a su lado, la grúa oxidada de un viejo aserradero que conservaba el nombre de sus fabricantes: TALLERES UNURSA. BILBAO.

(p. 156)

El lugar donde Pilar queda secuestrada es muy simbólico: una antigua propiedad de los españoles. Con esto, Mbama parece utilizar las herramientas y los medios facilitados por los mismos antiguos colonizadores para una especie de ajuste de cuentas con los españoles. En el discurso de Mbama se puede leer esa intencionalidad represiva: cuando habla de Pilar recuerda los tiempos de colonización cuando él trabajaba como " esclavo» para los españoles (p. 165). Se entiende entonces que el secuestro de Pilar sea considerado como una esclavitud « sexual», cuyo fruto es el nacimiento de una niña no deseada por la madre: « No quiero tener ese hijo, doctor Luis» (p. 160) dice Pilar al médico que acudió para ayudarle en el parto. Más allá del secuestro, tal vez sea la consciencia de esa esclavitud lo que finalmente le causó un trauma que se llevó la vida de la española. Pilar considera a la niña que resultó de la relación con Mbama como un testimonio de su sujeción, de su esclavización, de su libertad robada. Ante la imposibilidad de no tener esa niña, prefiere no vivir (p. 160). Pilar decide poner fin a sus días en este sentido, pues unas semanas después de sus confidencias al doctor Luis Urzaiz, Mbama anuncia a éste la muerte de su « compañera»:

No quería comer, no quería ver a la niña. Y dos semanas después de que Ciriaca naciera, la encontraron muerta en la habitación: se había ahorcado. (p. 164)

Pilar prefiere abreviar su vida a la humillación, a la esclavitud y al deshonor: cosas que parecía denunciar Mbama al referirse a la situación poco agradable de los Negros durante la colonización.

\section{El padre Diego}

El personaje del padre Diego se asocia a la educación moral y religiosa: es un cura que se instaló en Guinea cuando el país era todavía una colonia española. Refiriéndose a su vinculación con la población africana y la importancia de su labor, el padre Diego dice estar entre los Negros para sanar su alma. Como se puede notar en el siguiente fragmento (una conversación entre el padre Diego y Luis Urzaiz), establece un paralelismo entre la labor del médico, Luis Urzaiz, y la suya: "Yo les ofrezco consuelo, les ofrezco sanarlos en el hospital (...), cuando es posible hacerlo -Es compatible sanar el cuerpo con sanar el alma. El mío y el tuyo son dos trabajos distintos. Pero, ambos se dirigen a salvar el hombre" (p. 61).Varios detalles en los discursos del padre Diego convergen hacia una idea única y firme sobre la sociedad guineana: son unos salvajes, perversos y poseídos por el diablo.

De la administración guineana no se fía y lleva a Luis a disuadirse ante cualquier tentación de colaborar con ella:

¿La policía guineana? No me hagas reír, Luis; parece que hubieras llegado ayer. Sabes que son una reata de corruptos dirigidos por un capataz que es un mafioso y un gángster. ¿Cuándo has confiado en la policía de este país? En los tiempos de la presidencia de Macías estaba más dedicada a preparar asesinatos que a intentar evitarlos. Y en los de Obiang, en lugar de perseguirlos, los organiza. (pp. 57-58)

\section{II.1.2. La colonización como misión civilizadora}

Este aspecto es el resultado de los aspectos ya expuestos anteriormente: la caracterización idealizada de los personajes y de su misión salvadora entre los Negros que ya 
señalamos parece tener una meta: presentar la colonización, entendida como la acción de unos colonos sobre una sociedad en estado de naturaleza, como una misión civilizadora, ya que los Blancos llevan proyectos salvadores: esos proyectos (salud física y mental, salud moral y educación) se presentan como las únicas garantías para el bienestar, el progreso y la civilización.

\section{II.2.España como sociedad ideal}

La presentación de España como espacio cultural ideal en contraposición a la sociedad guineana (africana en general) es muy frecuente en el relato.

Guinea es un espacio inhóspito, peligroso para la vida humana. En este fragmento, el padre Diego se lo recalca a Luis Urzaiz:

¡Demonio de calor ¡-dirigiéndose a Luis -Jamás me acostumbraré a Guinea. Y mira que en mi tierra pega el sol (...). Pero no es como aquí ¡Esta humedad (...)! -Tenemos un destino parecido. Los dos vamos a morir aquí, en esta tierra llena de mosquitos malignos, gentes embrutecidas y calor insufrible" (pp. 54-55).

Por otra parte, en el mismo relato se refiere al espacio guineano como un país de "viviendas miserables" (p. 16), sin comida (p. 13) etc., un cuadro espacial lúgubre y sin esperanzas. En unos fragmentos se asimila Guinea al infierno: "Luis vivía en el infierno" (p. 173).

En cambio, los únicos microespacios donde aparece la luz son las que acogen las realizaciones españolas en el país: "una iglesia católica de empinadas escalinatas que recuerda al palacio del Conde Drácula", "un colegio de monjas españolas", "un hospital construido en la época de la colonia española y una sólida casa de dos plantas" (p. 14). Estos elementos que transforman los microespacios guineanos son una proyección mental de la sociedad española en el espacio africano, una presencia de la luz en una inmensa oscuridad. Pero el narrador señala que la presencia de la civilización española en ese espacio no es sino una pálida muestra de la realidad vivida en espacio de origen: "Allí los hospitales son mejores. Hay varios aviones por semana que vuelan..." (p. 32).

\section{Conclusiones}

La Canción de Mbama, como relato de viaje reúne casi todos los rasgos del género, desde las perspectivas estructural y estilística: la historia se construye entorno a unas coordenadas espacio-temporales acordes con la tradición de la literatura viática. El relato ofrece una profusión de datos históricos, sociológicos y culturales, convirtiéndose en un texto de carácter documental. El autor hace una hábil combinación de la descripción y de la narración, alude a personajes históricos (Macías Nguema, Teodoro Obiang Nguema, Kofi Annan etc.), espacios de geografía empírica (Guinea, Cogo, Río Muni, Bata, Evinayong, Gabón, Nigeria...) Pero los aspectos examinados en este trabajo se refieren a las técnicas de representación de las realidades africanas (espacio, personajes, cultura). Al término del análisis, se confirman las hipótesis iniciales pues el relato nos revela una inclinación del autor a una escritura dictada por lo que llama Zygmunt la "ideología del viaje", es decir "el conjunto de ideas y creencias que se asocian al viaje, su forma, su objetivo y su sentido" (Zygmunt, 2013:7). El texto consiste principalmente en unas representaciones organizadas entorno a dos modalidades: por una parte, un retrato esperpéntico de las realidades africanas (distopía) que apuntan unos aspectos tan feos que parecen reflejar finalmente una sociedad ficticia indeseable. La utilización de este estilo podría tener como clave de lectura un compromiso crítico con una esperanza de cambios. Por otra parte el autor recurre a una utopia 
al presentar la sociedad española (occidental) como un orden social perfecto, contrapuesto a las realidades negroafricanas.

\section{REFERENCIAS BIBLIOGRÁFICAS}

ABAD, B. (2013): “La utopía y la distopía como herramientas de crítica social”, en Mecánico Unicornio. Revista de Ciencia Ficción y Utopía, num. 2 (diciembre), en línea.

ACOSTA, V. (1993): Viajeros y maravillas. Caracas, Torino.

ALBURQUERQUE GARCÍA, L. (2011): "El relato de viajes: hitos y formas en la evolución del género", en Revista de literatura, enero-junio, vol. LXXIII, Nº 145.

ÁLVAREZ DE MIRANDA, P. (1995): "Sobre los libros y relatos de viajes en el siglo XVIII", en Literatura de viajes, monográfico de Compas de letras, 7, pp.97-96.

ASCANO GARCÍA, P. (2010): Guinea Ecuatorial de colonia a sultanato. Madrid, Universidad Complutense.

BELTRÁN, L. y Duque García, I. (2007): Palabras de viaje. Estética y hermenéutica del viaje, Bellcaire d'Empordá. Vitel.la.

BOU, E. (2012): Invention of space. Madrid, Iberoamericana.

COVO, J. (ed.) (1994): Las representaciones del tiempo histórico. Lille, Presse Universitaire de Lille.

CROS, E. (2009): La sociocrítica. Madrid, Arco Libros.

CROS, E. (1992): Ideosemas y Morfogénesis del texto. Literatura española e hispanoamericana. Frankfurt am Main, Vervuert.

KRUMMRICH, P. (2012) "Historias de caníbales: una parodia de las narrativas de viaje", en LEJANA. Revista Crítica de Narrativa Breve $\mathrm{N}^{\circ}$ 5, pp. 1-5.

LE HUENEN, R. (1995) : “Qu'est-ce qu'un récit de voyage?”, en les Modèles de récit de voyages, monográfico de Literales, 7, 11-25.

ROMERA CASTILLO, J. (1977): Comentario de textos semiológico. Madrid, SGEL

VILLAR DÉGANO, J. F (1995): "Paraliteratura y libros de viajes", en Literatura de viajes, monográfico de Compás de letras. 7, pp.15-32.

ZYGMUNT, K. (2013): "La construcción de la experiencia del viaje en la escritura: figuras del escritor viajero contemporáneo", en Kamtchatka, número 2 (diciembre), pp. 105134.

(C) Antoine Bouba Kidakou

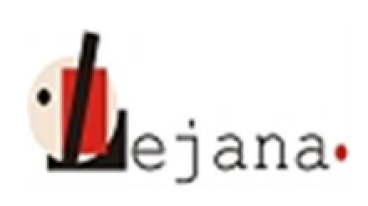

http://lejana.elte.hu

Universidad Eötvös Loránd, Departamento de Español, 1088 Budapest, Múzeum krt. 4/C

Recibido: 06 de junio de 2015

Aceptado: 13 de septiembre de 2015 